\title{
RESPONSE STRATEGIES OF ADULT MALE SCHIZOCOSA CRASSIPES (ARANEAE: LYCOSIDAE) DURING AGONISTIC INTERACTIONS ${ }^{1}$
}

\author{
BY WAYNe P. ASPEY2 \\ Department of Zoology and Microbiology \\ Ohio University, Athens, Ohio 45701
}

\section{INTRODUCTION}

This paper represents one of a series (Aspey, 1975a, b, 1976a,b,c) on the ethology and behavioral ecology of the brush-legged wolf spider Schizocosa crassipes (Walckenaer). Among lycosids, the adult males of this species are unusual in that they exhibit an elaborate and extensive behavioral repertoire during agonistic interactions (Aspey, 1976b). As immatures, the spiderlings exhibit a characteristic leg wave display that spaces conspecifics and presumably minimizes cannibalism (Aspey, 1975a). As adults, the males develop black foreleg brushes and exhibit the complex behaviors seen exclusively during adult male-male agonistic interactions. This display is primarily a visually-mediated communication system that preserves the personal space of adult males (Aspey, 1976c).

These spiders are found in dense abundance among leaf litter at the forest-meadow interface, and share characteristics typical of "edge" species (Aspey, 1976a). Furthermore, males are more active than females, and in the natural habitat during a given oneminute observation period, an adult male is likely to encounter three males to one female. By exhibiting one or more of the foreleg movements and/or postures comprising the behavioral repertoire, certain males drive other males away from the female while remain-

\footnotetext{
1This study was partially supported by a Hiram Roy Wilson Research Fellowship in Zoology, and represents portions of the author's Doctoral Dissertation submitted to Ohio University. Publication was aided by the Marine Biomedical Institute at The University of Texas Medical Branch, Galveston, Texas 77550.

${ }^{2}$ Present address: Division of Comparative Neurobiology \& Behavior, The Marine Biomedical Institute, The University of Texas Medical Branch, 200 University Boulevard, Galveston, Texas 77550 .
}

Manuscript received by the editor March 15, 1976. 
ing in the female's vicinity. Thus, the extensive agonistic behavioral repertoire may also confer a mating advantage to those males most successful in driving other males away from the female.

Although this hypothesis has not yet been demonstrated experimentally, the males do exhibit stable, linear dominance-subordinance relations among themselves when tested in the laboratory under varying social, spatial, and population densities (Aspey, $1975 \mathrm{~b}, 1976 \mathrm{~b}, \mathrm{c})$. Using a variety of analytical and descriptive techniques, each adult male $S$. crassipes can be classed as Dominant, Intermediate, or Subordinate in terms of the kinds and frequencies of agonistic behaviors exhibited during male-male encounters. Although the dominance classification is based on one animal's responses to an opponent (i.e., inter-individual behaviors), this study demonstrates that strikingly different response strategies are also adopted by Dominant and Subordinate spiders when intra-individual behavior sequences are analyzed

\section{METHODS}

\section{Subjects}

The subjects were 40 adult males of the ground-dwelling brushlegged wolf spider Schizocosa crassipes (Walckenaer) (body length $=7-10 \mathrm{~mm}$; carapace width $=3-4 \mathrm{~mm}$; leg span $=27-30 \mathrm{~mm}$ ). Molting to the adult occurs in late May, at which time the males develop conspicuous tufts of black hairs on the tibiae of the forelegs, with smaller brushes on the patellae. The spiders were collected as immatures among leaf litter in early May at Stroud's Run State Park. Athens, Ohio, U.S.A., and housed individually in visually-isolated, covered plastic containers $(12.5 \times 7.0 \times 7.0 \mathrm{~cm})$ until $1 \mathrm{wk}$ after the final molt. Seven to ten days after the final molt each spider was marked with nontoxic enamel paint ("Pactra 'namel," Los Angeles, CA) on the dorsal surface of the cephalotho$\operatorname{rax}$ and/or abdomen. No detrimental behavioral effects were apparent following paint application.

All spiders were tested in four groups each of two, three, or five spiders matched into size categories of $0.5 \mathrm{~mm}$ increments based on adult carapace width (Hagstrum, 1971). Behavioral observations were made in various sized rectangular glass terraria $(90,180$, 270 , or $540 \mathrm{~cm}^{2}$ floor space) having paper substrata strewn with 
dried leaves. Three of the four glass walls of each terraria were shielded with white paper on the outside to minimize external visual distractions. Each terrarium was covered with glass to prevent escape and to maintain relatively constant humidity conditions $\left(24.5^{\circ} \mathrm{C} \pm 1.0 \mathrm{SD} ; 60.0 \%\right.$ R.H. $\left.\pm 2.0 \mathrm{SD}\right)$. Water was available ad libitum from cotton-plugged vials, and food consisted of larvae of the yellow mealworm beetle Tenebrio molitor offered twice weekly. Photoperiod consisted of 16-17 hr of continuous artificial light alternated with 7-8 hr of continuous darkness.

\section{Data Collection}

Observations were conducted from early June through late July, 1973, and data collection began 5-7 days following marking of the animals. Each observation terrarium rested on a styrofoam block placed on a separate table from the recording equipment to reduce vibrations, and I was positioned $45 \mathrm{~cm}$ in front of the chamber. Protocol during all male-male interactions was tape-recorded and data were transcribed at a later date. Following transfer to the observation terrarium, subjects were observed for 10 consecutive days at approximately the same time. The frequencies of each behavior comprising the agonistic behavioral repertoire of $S$. crassipes during adult male-male interactions (Aspey, 1976b) were recorded continuously throughout the observation period. Since the duration of each observation period varied with the number of spiders present (with $\mathrm{N}=2$ the observation period lasted $20 \mathrm{~min}$; with $\mathrm{N}=3,25$ min; with $\mathrm{N}=5,35 \mathrm{~min}$ ), the data were adjusted to yield mean frequences of each behavior per $20 \mathrm{~min}$.

An interaction was considered to occur when one spider approached within $3-5 \mathrm{~cm}$ of another spider; data were discarded when two spiders simply passed one another without orienting or displaying to one another. An interaction was considered to continue when one spider chased or pursued a retreating spider. An interaction was considered terminated if an animal fled or was actively driven away by another spider. An interaction was considered to involve only two spiders because interactions among three or more spiders occurred only twice.

\section{Transitional Probabilities}

To determine predictable behavior sequences for individual spiders, an intra-individual transition probability matrix was con- 
structed in which the preceding acts are listed as the horizontal rows and the following acts are listed as the vertical columns (Table I).

Such a matrix indicates how frequently given behaviors immediately follow or precede other specific behaviors, and similar techniques have been employed by a variety of investigators (Andrew, 1956; Altmann, 1965; Hazlett and Bossert, 1965; Delius, 1969; Wilson and Kleiman, 1974). The construction of an inter-individual transition probability matrix to determine which behaviors were exhibited by one spider in response to another's behavior is discussed in Aspey (1976b). Although procedures for constructing the intra-individual transition probability matrix of the present study are fundamentally the same as for the inter-individual transition probability matrix (Aspey, 1976b), no attention was paid in this analysis to acts performed by other spiders and their possible influence. To obtain the matrix, the complete sequence of agonistic behaviors was broken down into a series of two-act sequences. To illustrate, the four-act sequence Jerky Tapping - Following Walk - Oblique Extend - Vibrate-Thrust, provided three twoact sequences: Jerky Tapping - Following Walk, Following Walk - Oblique Extend, and Oblique Extend - Vibrate-Thrust.

To determine when any two behaviors performed by the same spider were significantly linked beyond chance expectation, the method developed by Andrew (1956) and employed by McKinney (1961) and Wilson and Kleiman (1974) was used. Two behaviors were considered significantly linked if the difference between the observed and expected values was greater than three times the square root of the expected value. In other words, the square root of the observed value was estimated as the standard error of the expected value, and a difference of more than three times the standard error between the obtained and expected totals was regarded as significant with a deviation of 2.58 times the standard error corresponding to $\mathrm{p}<0.01$ level of significance. With large samples the distribution was the same as for chi-square; however, Andrew's method was not restricted by the assumptions of chi-square, namely it: (1) did not assume independence of each variable; (2) allowed expected frequencies of zero; and (3) allowed expected frequencies for five or fewer in more than $20 \%$ of the cells. Therefore, Andrew's method had the same power as chi-square but allowed for the analysis of infrequently occurring behaviors, and did not assume that all 


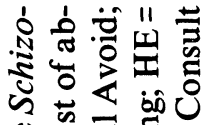

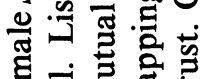

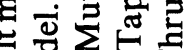
至 政 क्ष 政

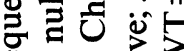

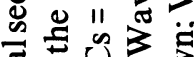
可 을

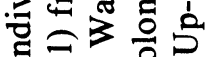
T)

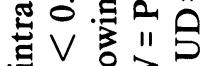

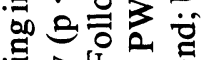

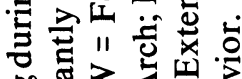

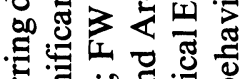
管 政

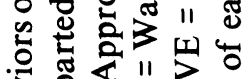

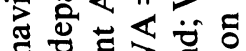
잉

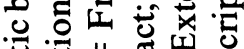
.

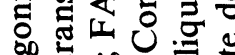

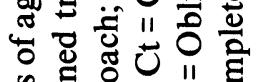

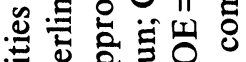

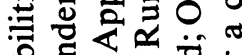
尊 51111 웅

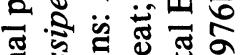
s.

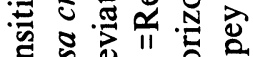

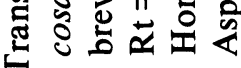

苛

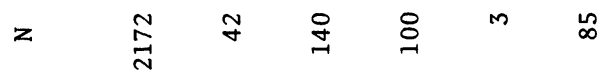
袢

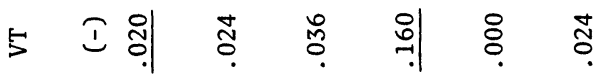
ร ข س य

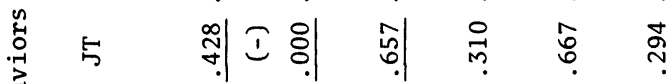
₹ ₹

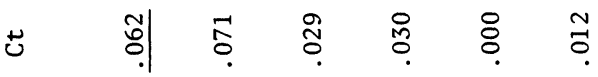

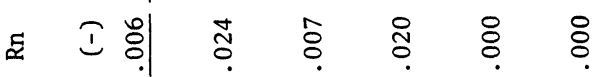
ะ

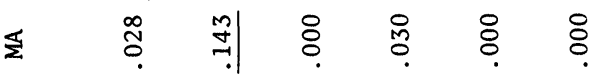

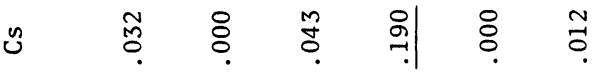
₹ «

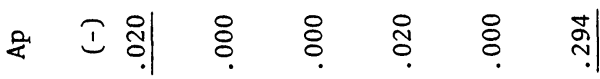

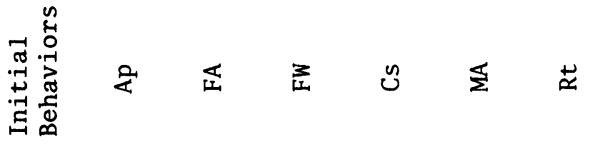




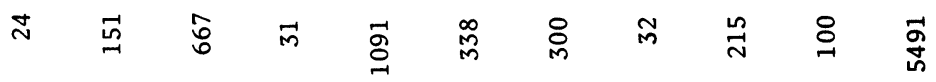

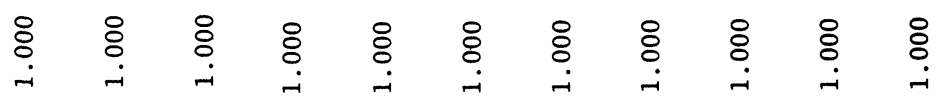

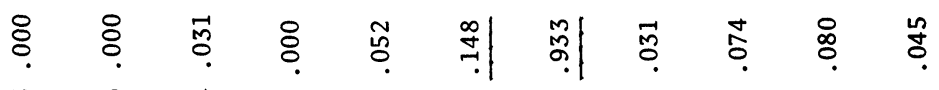

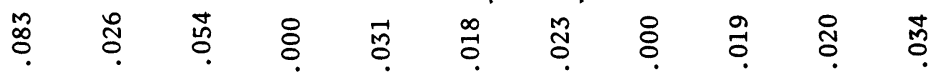

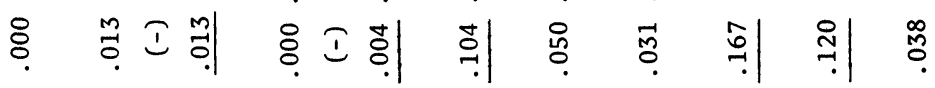

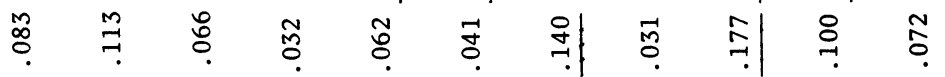

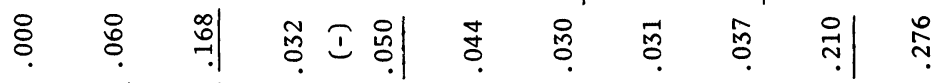

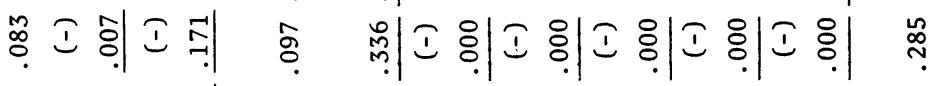

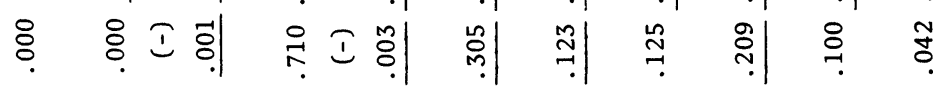

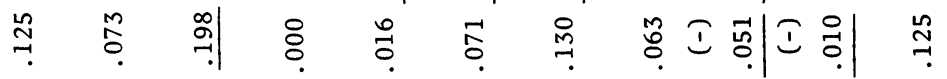

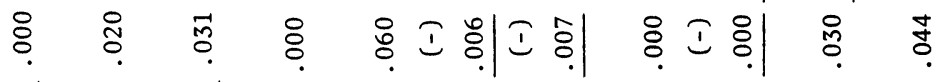

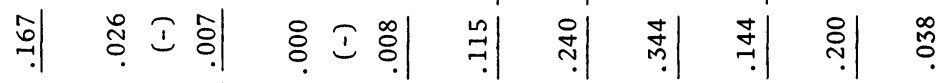

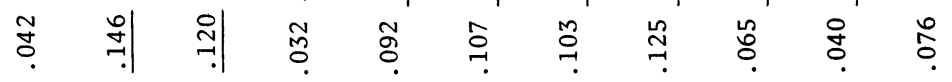

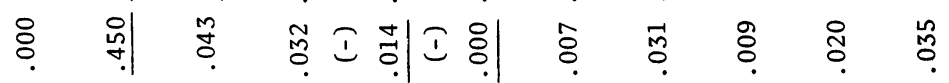

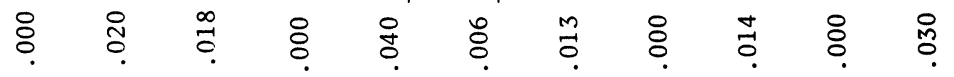
\& \&

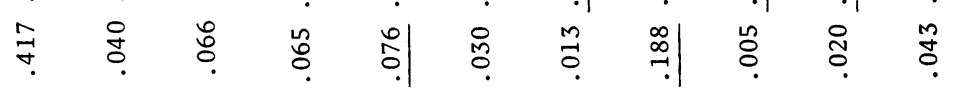

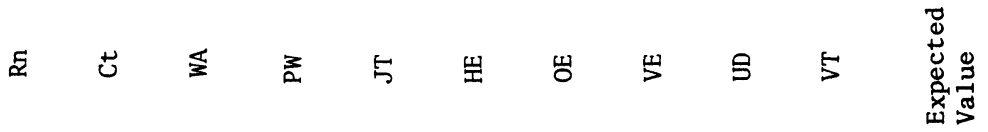


variables were necessarily independent. Underlined transitions in Table I indicate those behaviors linked to one another which departed significantly $(p<0.01)$ from the null order model. Negative linkages are marked (-), indicating that certain behaviors occurred less frequently than expected by chance.

\section{RESULTS}

\section{Transitional Probabilities}

A total of 3,525 adult male-male agonistic interactions were recorded in the laboratory that included 14,109 behavioral acts. The original 20 agonistic behaviors were found to be better represented by 16 behavior categories, and the rationale for this consolidation is discussed in Aspey (1976b). When the data were cast into a $16 \times 16$ matrix, the occurrence of significant deviations from expected frequencies suggested a probabilistic structure to the intra-individual agonistic behavior sequences (Table I). Of 256 possible linkages from a $16 \times 16$ matrix, 37 occurred more frequently than expected by chance, while 30 occurred less frequently. With regard to only the foreleg movements and postures exhibited during agonistic interactions (Aspey, 1976b), a wider variety of subsequent behaviors occurred during intra-individual sequences than during inter-individual behavioral responses. For example, during intra-individual sequences, an average of 5.6 different agonistic behaviors followed a given foreleg movement or posture beyond chance levels, while only 2.6 different behaviors followed a given foreleg movement or posture during inter-individual encounters (Aspey, 1976b).

\section{Sequential Behaviors of Dominant and Subordinate Spiders}

Since adult $S$. crassipes could be characterized as Dominant or Subordinate on the basis of the kinds and frequencies of agonistic behaviors exhibited during male-male interactions (Aspey, 1975b, 1976b), profiles of Dominant and Subordinate spiders were constructed using intra-individual behavior sequences. Although the original dominance classifications of the spiders utilized responses from one spider toward another, this method of characterizing Dominant and Subordinate spiders emphasized behavioral sequences exhibited by individual spiders. 
Intra-individual behavioral sequences are diagrammed separately for the 16 Dominant spiders (Figure 1) and 16 Subordinate spiders (Figure 2). Dominant spiders were characterized by those agonistic behaviors comprising Factor I (Approach/Signal) and Factor II (Vigorous Pursuit) of Aspey's (1976b) factor analytic classification. Subordinate spiders were characterized by Run, Retreat, and Vertical Extend, those behaviors comprising Factor III (Run/Retreat) of Aspey's (1976b) factor analysis of the agonistic behavioral repertoire. A comparison of the original 20 behaviors displayed by Dominant and Subordinate spiders revealed that Dominant spiders exhibited a wider variety of behaviors linked together (15 out of a possible 20) than did Subordinate spiders (10 out of 20). Thus, these results indicate that Dominant and Subordinate spiders can not only be reliably identified on the basis of responses made by conspecifics toward them during agonistic interactions (Aspey, 1976b), but also by the response strategy exhibited during intraindividual behavior sequences.

\section{DISCUSSION}

A transition probability matrix of agonistic behaviors exhibited during adult male-male interactions in $S$. crassipes indicated that a wider variety of responses followed any given behavior by a single spider during intra-individual sequences than during inter-individual encounters (Aspey, 1976b). However, examination of Table I revealed that some of the sequential responses appeared inconsistent (e.g., Run or Vibrate-Thrust following the performance of Horizontal Extend; Run or Front Approach following the peformance of Vibrate-Thrust). Horizontal Extend and Vibrate-Thrust are signal and active pursuit behaviors, routinely followed by some form of retreat during inter-individual encounters (Aspey, 1976b). However, if an animal exhibited Horizontal Extend or VibrateThrust, seemingly aggressive behaviors, why would it suddenly retreat immediately after performing such a behavior?

Further analysis examining each specific spider indicated that some spiders were consistently Dominant over all partners, while others were consistently Subordinate to every partner. For example, Dominant spiders not only performed Horizontal Extend or Vibrate-Thrust more frequently, but also continued to exhibit Vigorous Pursuit behaviors if an initial encounter with a conspecific 


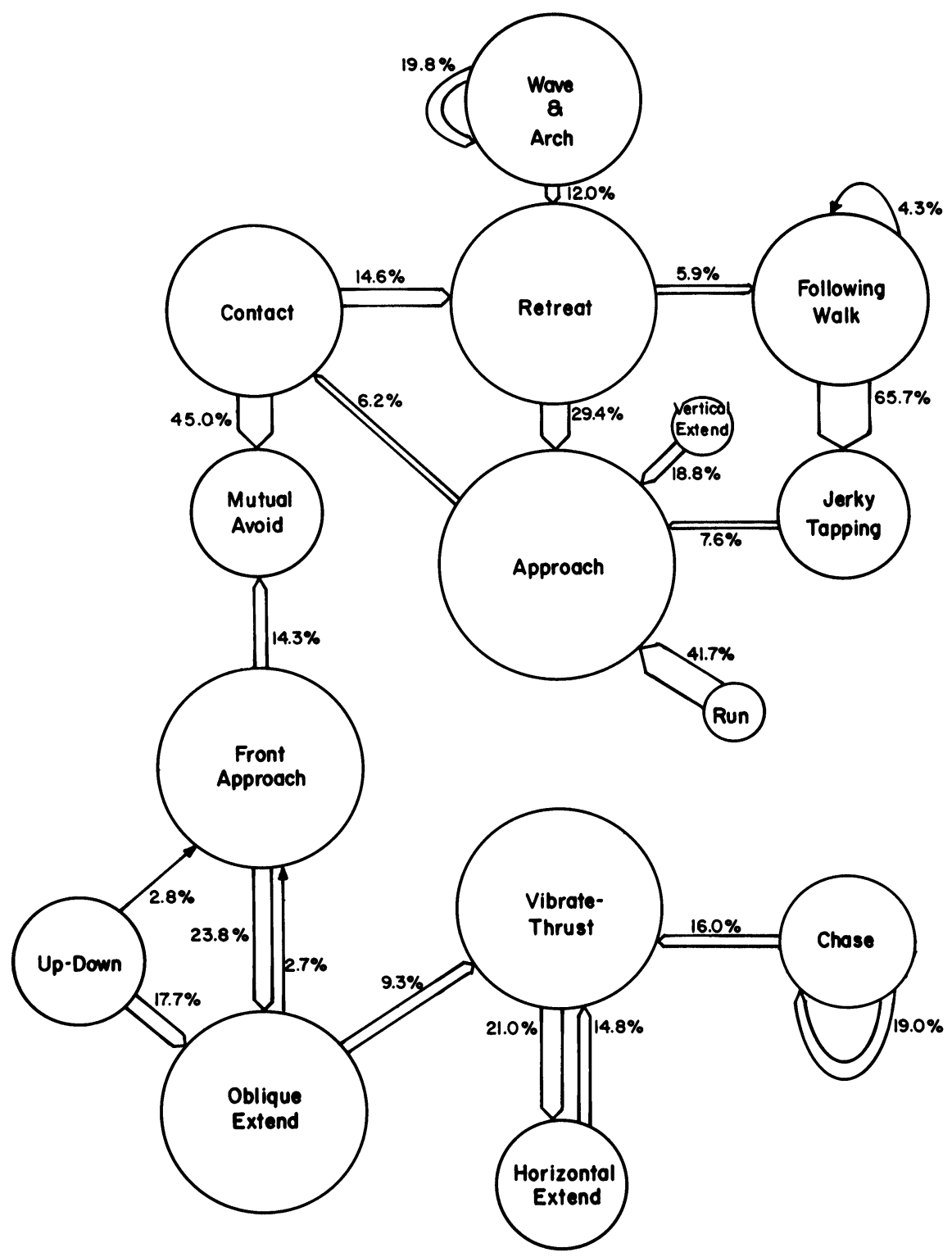


did not result in that animal's retreating. If Subordinate spiders performed Vibrate-Thrust or Horizontal Extend, they then reverted to retreating, avoidance behaviors. When transition probabilities were examined separately for Dominant and Subordinate spiders, striking differences in response strategies were evident. Although eight Intermediate spiders were also identified (Aspey, 1976b), a meaningful kinematic diagram of their intra-individual response strategy could not be constructed with so few spiders. However, Intermediate spiders were typically approach-oriented, and made Contact preliminary to resolving rank differences with Dominant opponents. With Subordinate opponents, Intermediate spiders exhibited Oblique Extend, the only time a foreleg posture characteristic of Dominant spiders was exhibited (Aspey, 1976b).

If these intra-individual behavior sequences reflect a spider's responsiveness to its own behavior (i.e., feedback), then Dominant spiders exhibit the potential for more versatile response strategies during agonistic interactions than Subordinate spiders, presumably allowing greater flexibility when responding to conspecifics. Hazlett and Estabrook (1974a,b) also reported similar results regarding the response behavior of winning animals. Thus, Dominant and Subordinate spiders can not only be reliably identified on the basis of responses made by conspecifics toward them during agonistic interactions, but also by the response strategy exhibited during intra-individual behavior sequences.

\section{ACKNOWLEDGMENTS}

I gratefully acknowledge Dr. Jerome S. Rovner, Department of Zoology and Microbiology, Ohio University, for his helpful guidance and encouragement throughout all phases of this research, as well as for his useful discussions of the material. Dr. H. Dijkstra and Dr. S.W.F. van der Ploeg, Free University, Amsterdam, The Netherlands, kindly offered helpful discussion and commented on

Fig. 1. [opposite] Transitional probabilities during intra-individual behavior sequences in Dominant adult male Schizocosa crassipes. Arrows connecting the agonistic behaviors represent significant linkages $(p<0.01)$ between and among the behaviors. The relative thickness of the arrows indicates the percent of time one agonistic behavior followed another. The relative size of each circle represents the number of different behaviors significantly linked with that behavior. Descriptions of the behaviors are given in Aspey (1976b). 


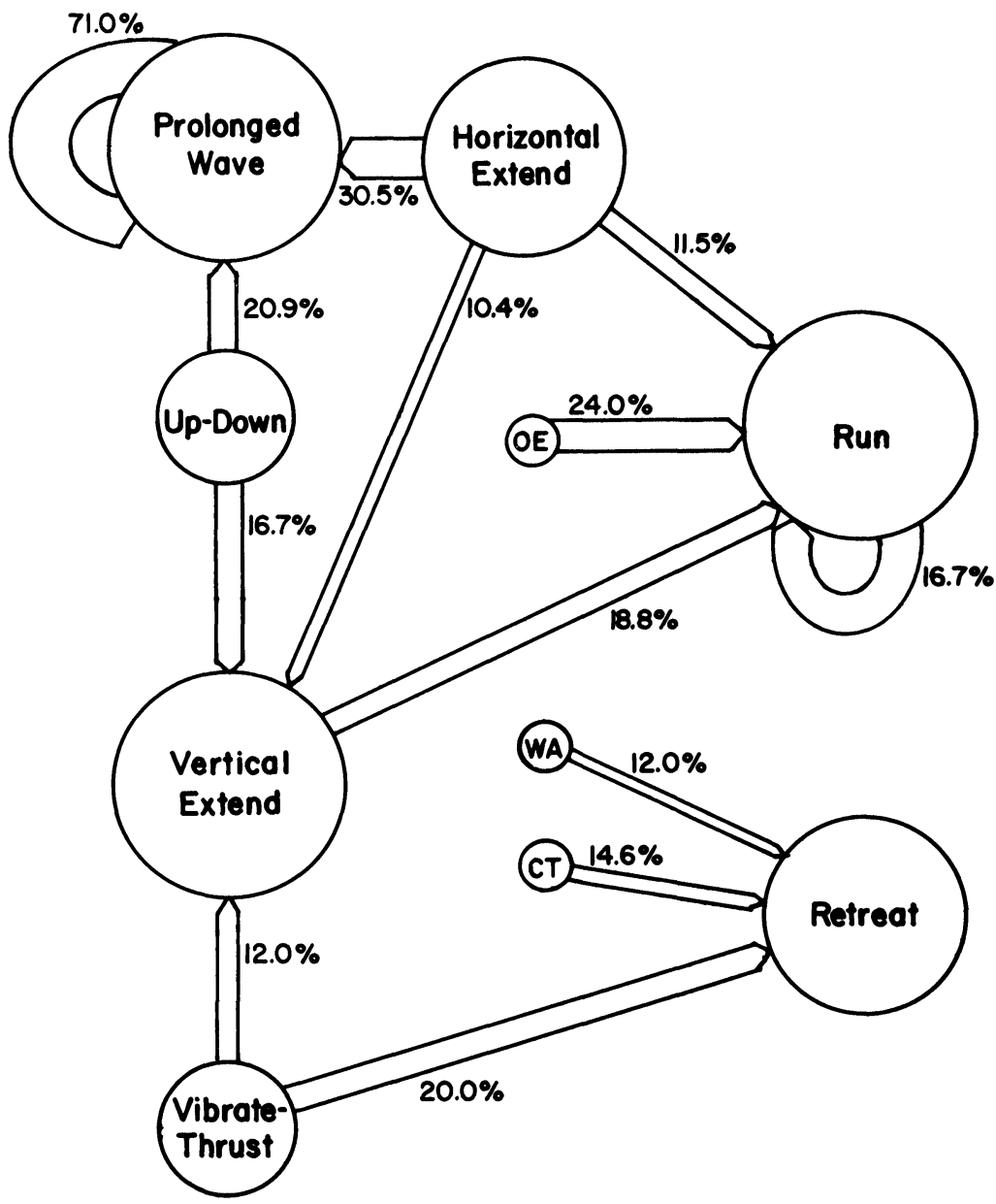

Fig. 2. Transitional probabilities during intra-individual behavior sequences in Subordinate adult male Schizocosa crassipes. Arrows connecting the agonistic behaviors represent significant linkages $(p<0.01)$ between and among the behaviors. The relative thickness of the arrows indicates the percent of time one agonistic behavior followed another. The relative size of each circle represents the number of different behaviors significantly linked with that behavior. List of abbreviations: $\mathrm{OE}=$ Oblique Extend; WA = Wave and Arch; CT = Contact. Descriptions of the behaviors are given in Aspey (1976b). 
the material. Dr. B. A. Hazlett, Department of Zoology, University of Michigan, Ann Arbor, and Dr. K. Nelson, Bodega Bay, California, provided valuable criticisms for improving earlier drafts of this work.

\section{Literature Cited}

Altmann, S. A.

1965. Sociobiology of Rhesus monkeys: II. Stochastics of social communication. J. Theor. Biol. 8: 490-552.

ANDREW, R. J.

1956. The aggressive and courtship behaviour of certain Emberizines. Behaviour. 10: $255-308$.

ASPEY, W. P.

1975a. Ontogeny of display in immature Schizocosa crassipes (Araneae: Lycosidae). Psyche. 82: 174-180.

1975b. Agonistic behavior and dominance-subordinance relations in the wolf spider Schizocosa crassipes. Proc. Sixth Int. Congr. Arach., Amsterdam, 1974. VI: 102-106.

1976a. Behavioral ecology of the "edge effect" in Schizocosa crassipes (Araneae: Lycosidae). Psyche. 83:42-50.

1976b. Wolf spider sociobiology: I. Agonistic display and dominance-subordinance relations in adult male Schizocosa crassipes. Behaviour (in press).

1976c. Wolf spider sociobiology: II. Density parameters influencing agonistic behavior in Schizocosa crassipes. Behaviour (in press).

Delius, J. D.

1969. A stochastic analysis of the maintenance behavior of skylarks. Behaviour. 18: $137-178$.

Hagstrum, D. W.

1971. Carapace width as a tool for evaluating the rate of development of spiders in the laboratory and the field. Ann. Entomol. Soc. Am. 64: 757-760.

Hazlett, B. A. AND W. H. Bossert

1965. A statistical analysis of the aggressive communications systems of some hermit crabs. Anim. Behav. 13: 357-373.

Hazlett, B. A. and G. F. Estabrook

1974a. Examination of agonistic behavior by character analysis. I. The spider crab Microphrys bicornutus. Behaviour. 48: 131-144.

1974b. Examination of agonistic behavior by character analysis. II. Hermit crabs. Behaviour. 49: 88-110.

MCKINNEY, F.

1961. An analysis of the displays of the European eider Somateria mollissima mollissima (Linnaeus) and the Pacific eider Somateria mollissima v. nigra Bonaparte. Behaviour (Supplement). 7: 1-124.

Wilson, C. S. AND D. G. Kleiman

1974. Eliciting play: A comparative study (Octodon, Octodontomys, Pediolagus, Phoca, Choeropsis, Ailuropoda). Am. Zool. 14: 341-370. 

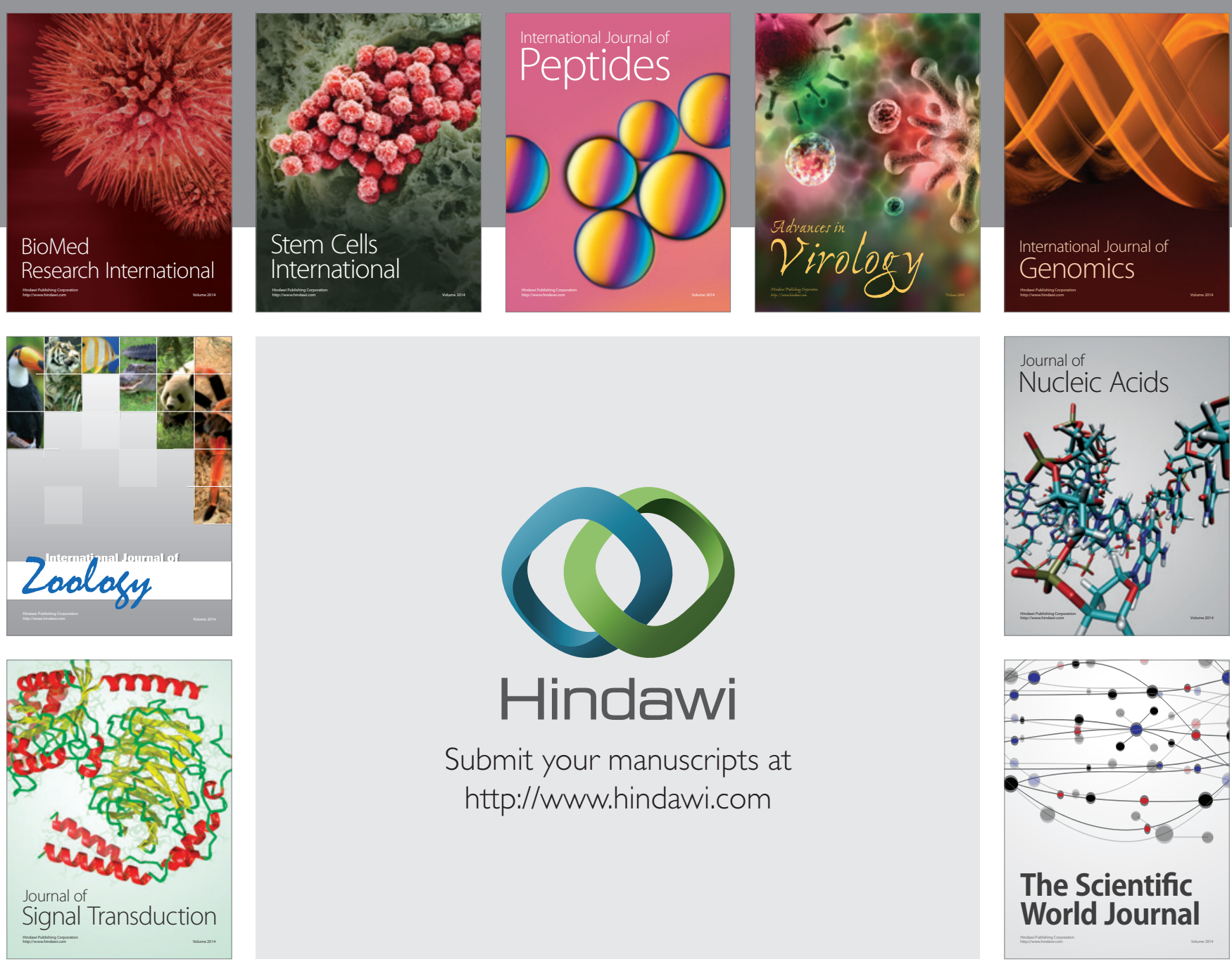

Submit your manuscripts at

http://www.hindawi.com
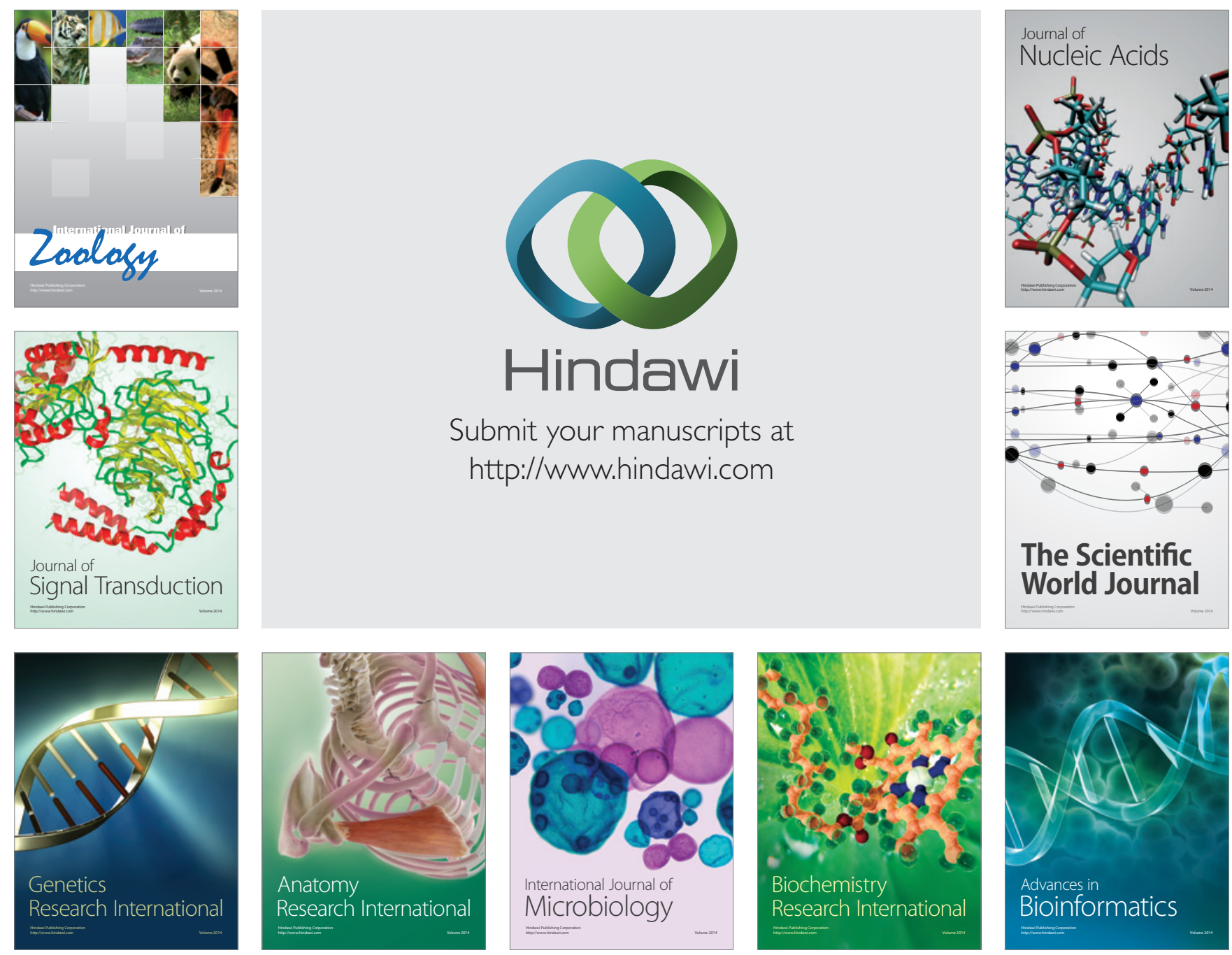

The Scientific World Journal
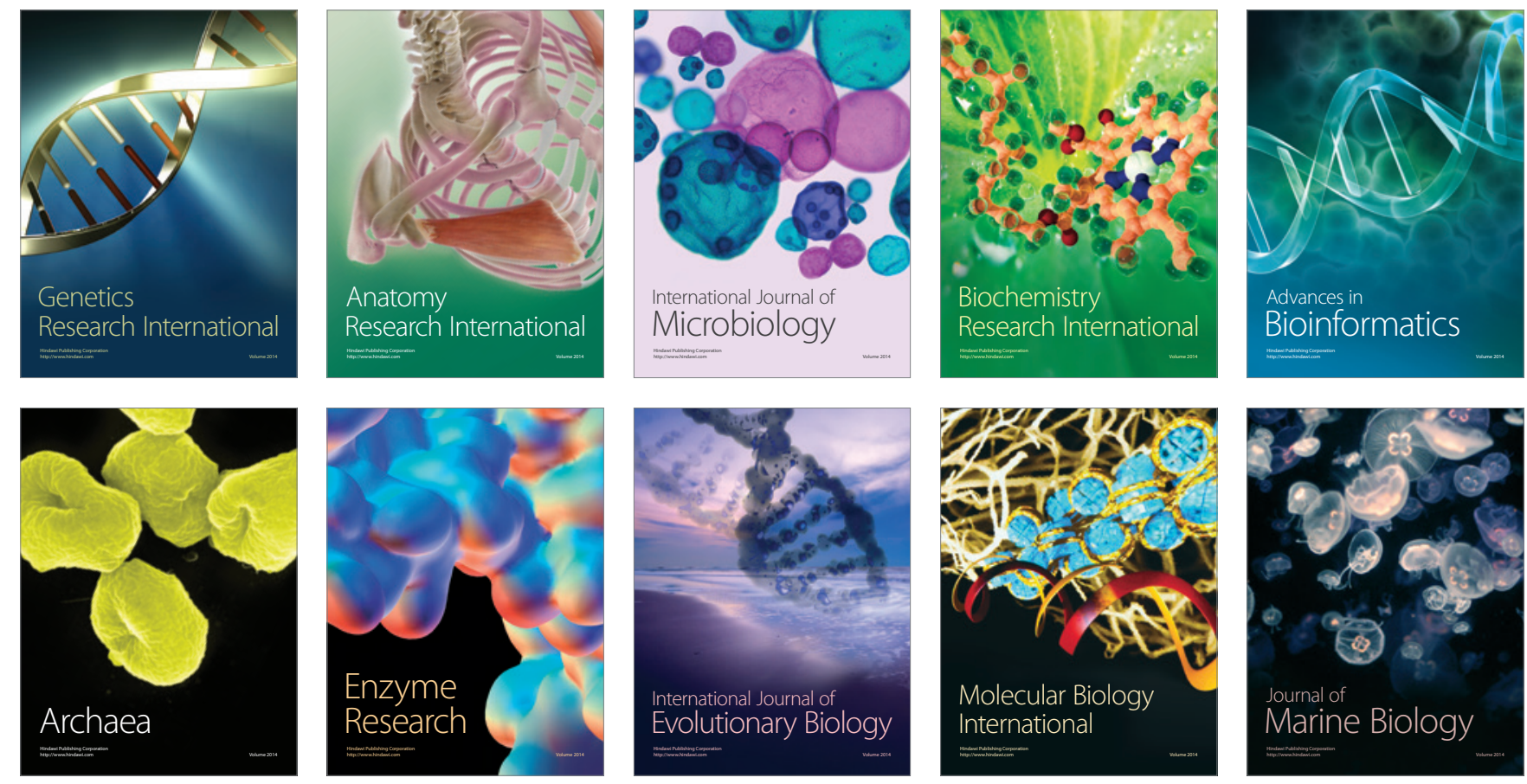